\title{
Comparative Analysis of Two Schemes of a Precision Vertical Machining Center
}

\author{
Qiang Cheng ${ }^{1,2, a}$, Guobin Yan ${ }^{1, b}$, Baobao $\mathrm{Qi}^{1, \mathrm{c}}$, Bawei Zhao ${ }^{3, \mathrm{~d}}$ \\ ${ }^{1}$ Beijing Key Laboratory of Advanced Manufacturing Technology, Beijing University of Technology, \\ Beijing 100124, China. \\ ${ }^{2}$ Key Laboratory of High Performance Complex Manufacturing, Central South University, Changsha, \\ Hunan, 4310083, China. \\ ${ }^{3}$ Shengke Inteligent Mechanical Manufacturing Co.,Ltd., Huaian, Jangsu, 223001, China. \\ achengqiangbjut@sina.cn, b1910734592@qq.com, ${ }^{\mathrm{c}} 1025642636$ @qq.com, \\ d2903835938@qq.com,
}

\begin{abstract}
This precise vertical machining center is a new type of product structure. In order to improve the performance of the machine tool, two kinds of bed structural design schemes are proposed. The bed structure of the first scheme is tilted, and the second scheme has a flat bed structure. The two kinds of structural design schemes are shown in Figure 1. Firstly, the two structures are analyzed theoretically, Then modal analysis of bed is carried out through ANSYS software . At last, the deformation of the key parts under the external force was analyzed. Through analysis and comparison, the optimal scheme of bed structure was obtained.
\end{abstract}

Keywords: Bed structure, odal analysis, deformation, optimal scheme

\section{Introduction}

CNC machining center is a typical machining equipment, with the characteristics of high precision, high speed, high efficiency and high automation. Besides, it can also meet the requirements of multiple varieties and small batch production [1]. With the increasingly fierce market competition, the demand for CNC machining center performance is getting higher and higher. Therefore, the designer of the machining center pays more attention to how to improve the performance of the machining center by improving the structure, morphology and dynamic model [2]. Ma Chao [3] summarized the design method of the machine tool structure and studied the design and application of the column. Yan Hua sheng [4] studied the dynamic design of the machine tool structure and put forward the key technology to optimize the structure of the machine tool. Zhang Xian dong [5] also analyzed the dynamic performance of machine tool structure. The analysis method of stiffness and vibration of Cui Lingli [6] provides guidance for improving the comprehensive performance of the machine tool. Liu Wen hua [7] design the structure of HMC63A horizontal machining center. Chen Shenghua [8] is used to optimize the structure of NC high speed milling machine tool by way of finite element analysis. The structure of the special machine tool is analyzed and designed by Monika [9]. Chen Xingguo[10] applied ANSYS software to optimize the structure of vertical machining center

\section{The two kinds of structural design schemes}

This precision vertical machining center is a new type of structural products. In order to i mprove the comprehensive performance of the machine tool, In the design of structure, two kin ds of bed structural design schemes are proposed are shown in Figure 1. In order to find out the best scheme, the two schemes are analyzed and compared in detail. 


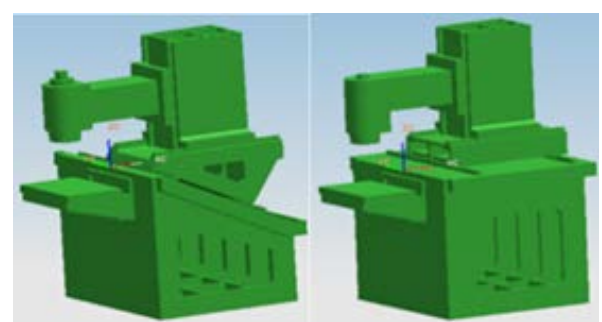

Fig. 1 Inclined bed and flat bed vertical machining center

\section{Comparison of two methods of theoretical analysis}

The bed body is fixed on the ground, it has little effect. So take the upper part of the bed as a whole research object. The gravity and static loads are only considered in the mechanical ana lysis. Therefore, from the direction of the left and the right limit position and the middle of the Y guide rail to simplify the calculation and comparison of the two schemes on the contact surfa ce of the different stress.

In the process of machining, the left guide rail is oriented guide rail. Therefore, The force $\left(\mathrm{N}_{12}\right)$ that perpendicular to the contact surface and the force $\left(\mathrm{N}_{11}\right)$ parallel on the contact sur face are considered. But the research object is suspended in the right track bed. Therefore, only the force $\left(\mathrm{N}_{22}\right)$ perpendicular to the contact surface is researched.

1)When it is in the middle position of the $Y$ guide rail. Scheme 1: the force analysis is sho wn in Fig 2-1. $\mathrm{P}_{1}=2451.66 \mathrm{~N}(250 \mathrm{Kg}) ; \mathrm{P}_{2}=784.53 \mathrm{~N}(80 \mathrm{Kg}) ; \mathrm{G}=6134.13 \mathrm{~N}(625.52 \mathrm{Kg})$. Barycentr ic coordinates (X, Z): (340.69 264.70) The guide rail is simplified to two supporting points $\mathrm{N}_{1}$ (240.62, -35) and $\mathrm{N}_{2}(742.90,-325) . \overline{\mathrm{N}_{1} \mathrm{~N}_{2}}=580 \mathrm{~mm}$. The static equilibrium equations are that:

$$
\begin{array}{ll}
\sum \mathrm{F}(\mathrm{x})=0, & \mathrm{~N}_{11} \cos 30^{\circ}+\mathrm{N}_{12} \cos 60^{\circ}+\mathrm{N}_{22} \cos 60^{\circ}-\mathrm{P}_{2}=0 \\
\sum \mathrm{F}(\mathrm{y})=0, & -\mathrm{N}_{11} \sin 30^{\circ}+\mathrm{N}_{12} \sin 60^{\circ}+\mathrm{N}_{22} \sin 60^{\circ}+\mathrm{P}_{1}-\mathrm{G}=0 \\
\sum \mathrm{M}\left(\mathrm{N}_{1}\right)=0, & -\mathrm{P}_{1}(264+240.62)+\mathrm{P}_{2}(210+35)-\mathrm{G}(340.69-240.62)+\mathrm{N}_{22} 580=0
\end{array}
$$

Get solution: $\quad \mathrm{N}_{11}=-1161.79 \mathrm{~N}, \quad \mathrm{~N}_{12}=721.30 \mathrm{~N}, \quad \mathrm{~N}_{22}=2859.98 \mathrm{~N}$,
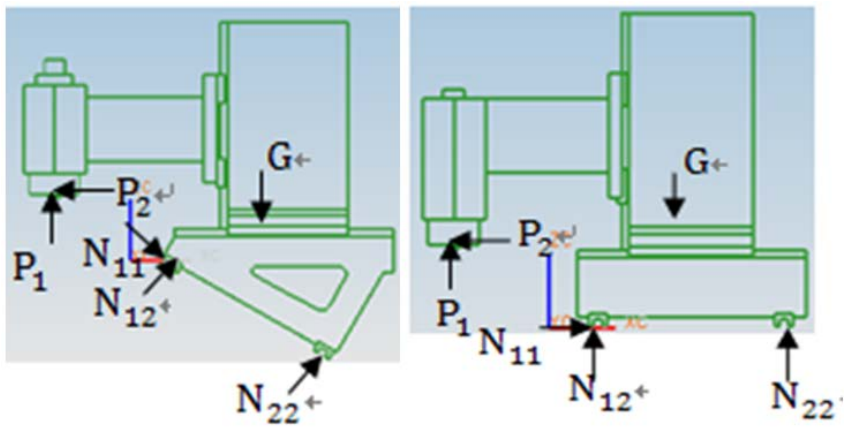

Fig. 2 Stress analysis of scheme 1 and scheme 2

Scheme 2: the force analysis is shown in Figure 2-2. $P_{1}=2451.66 \mathrm{~N}(250 \mathrm{Kg}) ; \mathrm{P}_{2}=784.53 \mathrm{~N}(8$ $0 \mathrm{Kg}) ; \mathrm{G}=6134.13 \mathrm{~N}(625.52 \mathrm{Kg})$. Barycentric coordinates (X, Z): (269.75, 405.52); The guid e rail is simplified to two supporting points $\mathrm{N}_{1}(159.6,30)$ and $\mathrm{N}_{2} \circ \overline{N_{1} N_{2}}=593 \mathrm{~mm}$. The static equilibrium equation is (2-2):

$$
\begin{array}{ll}
\sum \mathrm{F}(\mathrm{x})=0 & \mathrm{~N}_{11}=\mathrm{P}_{2}=784.53 \mathrm{~N} \\
\sum \mathrm{F}(\mathrm{y})=0 & \mathrm{P}_{1}-\mathrm{G}+\mathrm{N}_{11}+\mathrm{N}_{22}=0 \\
\sum \mathrm{M}\left(\mathrm{N}_{1}\right)=0 & -\mathrm{P}_{1}(304+159.6)+\mathrm{P}_{2}(234.5-30)-\mathrm{G}(269.75-159.6)+\mathrm{N}_{11} 593=0 \\
\text { Get solution: } & \mathrm{N}_{11}=784.53 \mathrm{~N}, \quad \mathrm{~N}_{12}=921.77 \mathrm{~N}, \quad \mathrm{~N}_{22}=2791.21 \mathrm{~N},
\end{array}
$$

Similarly, The state of stress in the left limit position and the right limit position of the $\mathrm{Y}$ guide rail can be analysed. The results are shown in table 2-1. The following results can be drawn from the analysis of the following table:

(1) with little difference in weight (6134.13 and 6164.64). Although the force parallel to the contact surface of scheme 1 is larger than scheme 2, but the force perpendicular to the contact surface of scheme 2 is larger than scheme 1 . Therefore, the bed left guide rail of scheme 2 has greater loading force, the damage caused by the process will be even greater. Since the left guide 
rail is a guide rail, it plays an important role in the process, it will have a great impact on the performance of the entire machine tool. Its destruction will have a great impact on the processing performance of the whole machine tool.

Table 1 Results comparison (unit: $\mathrm{N}$ )

\begin{tabular}{|c|c|c|c|}
\hline Position of force & $\mathrm{N}_{11}$ & $\mathrm{~N}_{12}$ & $\mathrm{~N}_{22}$ \\
\hline The middle position of & -1161.79 & 721.30 & 2859.98 \\
the X guide rail & 784.53 & 921.77 & 2791.21 \\
\hline The left limit position of & -1161.79 & 1326.03 & 2255.25 \\
the Y guide rail & 784.53 & 1397.75 & 2315.23 \\
\hline The right limit position & -1161.79 & 371.14 & 3210.14 \\
of the Z guide rail & 784.53 & 1836.22 & 1876.76 \\
\hline
\end{tabular}

(2)In the three position, analysis the stress of right guide rail in the two schemes. There is little difference between the two schemes of X intermediate position and X left limit position. For the stress of the $X$ limit position, although the scheme 1 is bigger than the scheme 2 . But the research object is suspended on the rail. Therefore, the force perpendicular to the contact surface has little damage to the right guide rail.

Based on the analysis, the scheme 1 is better than the scheme 2 in static analysis.

\section{Modal Analysis of Two Kinds of Bed Structures}

In the bed , the material is HT300. Its density is $7.3 \mathrm{e}-9\left(/ \mathrm{t}^{*} \mathrm{~mm}^{-3}\right)$, elastic modulus is $113-157$ E/GPa , poisson's ratio is 0.23-0.27. The modal analysis of the two schemes is shown in Figure 3.

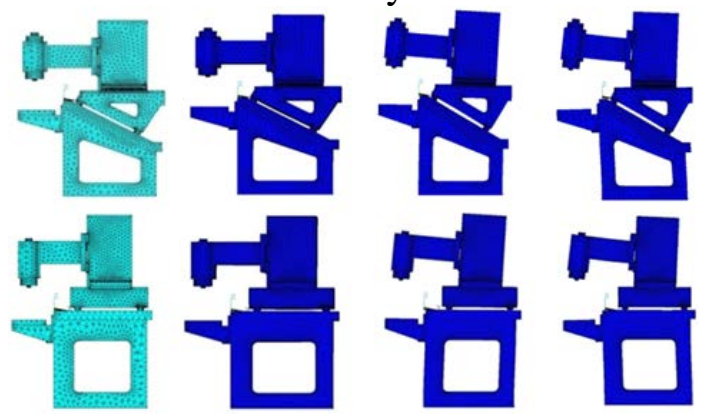

Fig. 3 The modal analysis of scheme 1 and scheme 2

From the 1 to the 10 mode, the frequency, deformation and critical speed of the two kinds of structural design schemes are shown in Table 2 and Table 3.

Table 2 From the 1 to the 10 mode, the frequency, deformation and critical speed of the scheme one

\begin{tabular}{|l|l|c|l|}
\hline & Frequency & Deformation amount & $\mathrm{n}$ \\
\hline First order & 96.155 & 2.543 & 5766.9 \\
\hline Second order & 96.842 & 2.588 & 5810.52 \\
\hline Third order & 146.044 & 2.494 & 8762.64 \\
\hline Fourth order & 155.306 & 2.352 & 9318.36 \\
\hline Fifth order & 241.444 & 2.065 & 14486.64 \\
\hline Sixth order & 258.946 & 4.374 & 15536.76 \\
\hline Seventh order & 269.816 & 2.11 & 16188.96 \\
\hline Eighth order & 346.87 & 2.536 & 20812.2 \\
\hline Ninth order & 363.712 & 2.356 & 21822.72 \\
\hline Tenth order & 528.928 & 4.959 & 31735.68 \\
\hline
\end{tabular}


Table 3 From the 1 to the 10 mode, the frequency, deformation and critical speed of the scheme two

\begin{tabular}{|l|l|c|l|}
\hline & Frequency & Deformation amount & $\mathrm{n}$ \\
\hline First order & 100.68 & 2.644 & 6040.8 \\
\hline Second order & 102.90 & 2.123 & 6174 \\
\hline Third order & 128.86 & 2.766 & 7731.6 \\
\hline Fourth order & 158.29 & 2.7778 & 9497.4 \\
\hline Fifth order & 265.09 & 2.03 & 15377.4 \\
\hline Sixth order & 277.46 & 2.275 & 16647.6 \\
\hline Seventh order & 289.04 & 2.539 & 17342.4 \\
\hline Eighth order & 315.92 & 4.506 & 18955.2 \\
\hline Ninth order & 377.86 & 1.677 & 22671.6 \\
\hline Tenth order & 481.44 & 5.071 & 28886.4 \\
\hline
\end{tabular}

From the above two tables, it can be seen that the critical velocity difference is 6214.8 between the ninth order and the tenth order in the scheme 2. However, the critical velocity difference is 9912.96 in the scheme 1. Obviously, It is indicated that the scheme 1 has a higher critical speed range at high speeds. Besides, the deformation $(4.959 \mathrm{~mm})$ of scheme 1 is less than the deformation $(5.071 \mathrm{~mm})$ of scheme 2 at tenth order mode.

\section{Stress and strain analysis of key parts under external loading}

According to the actual working conditions, the axial force of the spindle is $250 \mathrm{KN}$ and the radial force is $80 \mathrm{KN}$; Analysis of the workpiece quality on the workbench is $100 \mathrm{~kg}$.

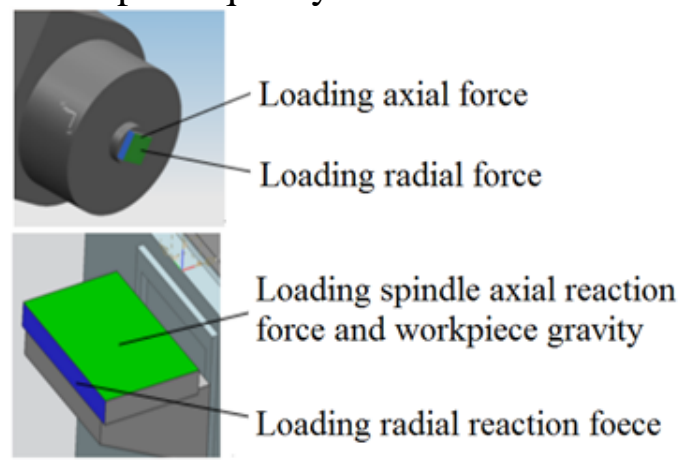

Fig. 4 Position and direction of loading external force on spindle and worktable

The area of the tool location is $30 * 30=900 \mathrm{~mm} 2$ So the pressure is $250 * 9.80665 / 900=2.7241 \mathrm{Mpa}$. The radial pressure is $80 * 9.80665 /(8.5 * 30)=3.0766 \mathrm{Mpa}$. Due to the size of the worktable is long $460 \mathrm{~mm}$, wide $320 \mathrm{~mm}$. The loading pressure on the table is $350 * 9.80665 /(320 * 460)=0.023317 \mathrm{Mpa}$, The surface pressure generated by radial force is $80 * 9.80665 /(460 * 50)=0.03411 \mathrm{Mpa}$.

(1)Comparing the strain and stress of $\mathrm{YZ}$ axis components in the middle position. The comparison of the strain between the $\mathrm{Y}$ axis and the $\mathrm{Z}$ axis component in the middle position is shown in Figure5, The maximum deformation position of the scheme 1 is outside the worktable, the maximum deformation is $0.020059 \mathrm{~mm}$; The maximum deformation position of the scheme 2 is near the spindle, and the maximum deformation is $0.020799 \mathrm{~mm}$. Comparison of deformation on the spindle, the deformation of the spindle is about $0.015602 \mathrm{~mm}$ in the scheme 1 . The deformation of spindle is more than $0.018488 \mathrm{~mm}$ in the scheme 2.For the deformation of the spindle, scheme 1 is about $0.03 \mathrm{~mm}$ smaller than scheme 2 . So the scheme 1 is better than the scheme 2. 


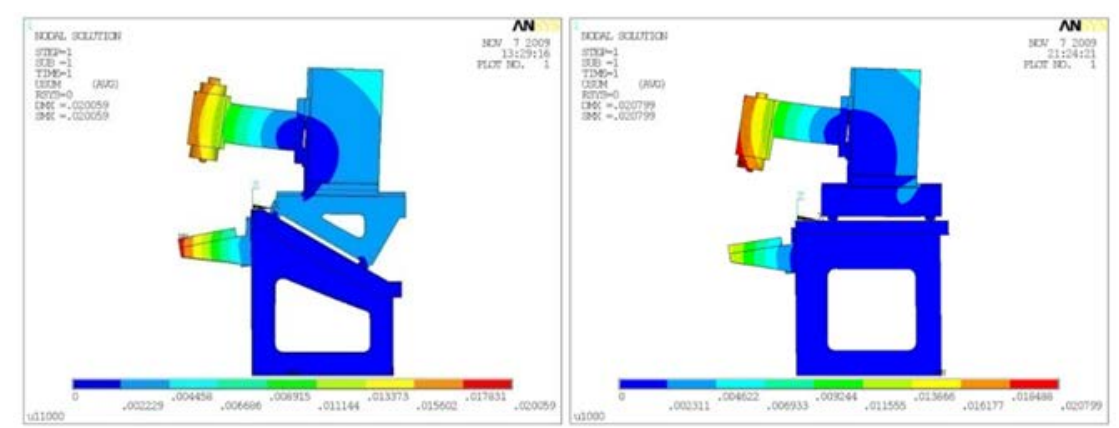

Fig. 5 external loading strain nephogram of scheme 1 and scheme 2

Similarly, you can compare the strain and stress of the YZ axis components in the upper right position 、 the YZ axis components in the top left position, the YZ axis components in the lower right position, and YZ axis components in the lower left position. The results of strain and stress in the above five positions. There are four positions show that the scheme 1 is better than the scheme 2 . The other position is almost the same of the two schemes.

\section{5 conclusion}

According to the analysis results of modal analysis and static analysis, the difference of scheme 1 and scheme 2 is was not significant in some aspects of the performance. However, from the comprehensive results, the structure of scheme 1 is better than the structure of scheme 2 . So the structure of scheme 1 is preferred

\section{References}

[1] Liu Dawei, Tang Liming. Development status and Prospect of domestic high-grade CNC machine tools [J]. aviation manufacturing technology, 2014,03:40-43.

[2] Xiao Lili. Structural optimization design and rapid simulation platform development of large Longmen machining center [D]. Nanjing University of Aeronautics \& Astronautics, 2011

[3] Ma Chao. Study on design method of machine tool structure and application of [D]. in the column design in Dalian University of Technology, 2010

[4] Yan. Research and application of dynamic design and optimization of machine tool structure [D]. Xiamen University 2008

[5] Zhang Xiandong. Application and Research on dynamic performance analysis and design of machine tool structure [D]. Tianjin University, 2005

[6] Cui L, Zhai H, Zhang F. Research on the meshing stiffness and vibration response of cracked gears based on the universal equation of gear profile[J]. Mechanism and Machine Theory, 2015, 94: 80-95.

[7] Liu Wenhua. The overall design of machine tool structure of HMC63A horizontal machining center [D]. Southwest Jiao Tong University, 2007

[8] Chen Shenghua. Finite element analysis and optimization of CNC high speed milling machine tool [D]. Nanjing University of Technology, 2005

[9]Monika Nowak,Daniel Jastrzębski. Selection of kinematic structure for portable machine tool[J]. Advances in Manufacturing Science and Technology,2012,36(1):.

[10] Chen Xingguo. Application of ANSYS in structural optimization design of vertical machining center [J] Metal Processing (Cold Processing), 2013, 19: 70-71. 